\section{Michigan Technological \\ 1885 University}

Michigan Technological University

Digital Commons @ Michigan Tech

\title{
Distributed Recycling of Post-Consumer Plastic Waste in Rural
}

\section{Areas}

\author{
M. Kreiger \\ Michigan Technological University \\ Gerald C. Anzalone \\ Michigan Technological University \\ M. L. Mulder \\ Michigan Technological University
}

A. G. Glover

Michigan Technological University

Joshua M. Pearce

Michigan Technological University

Follow this and additional works at: https://digitalcommons.mtu.edu/materials_fp

\section{Recommended Citation}

M. Kreiger, G. C. Anzalone, M. L. Mulder, A. Glover and J. M Pearce (2013). Distributed Recycling of PostConsumer Plastic Waste in Rural Areas. MRS Online Proceedings Library, 1492, mrsf12-1492-g04-06 http://digitalcommons.mtu.edu/materials_fp/51 
Published as: M. Kreiger, G. C. Anzalone, M. L. Mulder, A. Glover and J. M Pearce (2013). Distributed Recycling of Post-Consumer Plastic Waste in Rural Areas. MRS Online Proceedings Library, 1492, mrsf12-1492-g04-06 doi:10.1557/opl.2013.258.

\title{
Distributed Recycling of Post-Consumer Plastic Waste in Rural Areas
}

\author{
M. Kreiger, ${ }^{1}$ G. C. Anzalone, ${ }^{2}$ M. L. Mulder, ${ }^{1}$ A. Glover, ${ }^{1}$ and J. M Pearce ${ }^{1,3, *}$ \\ ${ }^{1}$ Department of Materials Science \& Engineering, Michigan Technological University, \\ Houghton, MI, United States. \\ ${ }^{2}$ Department of Civil \& Environmental Engineering, Michigan Technological University, \\ Houghton, MI, United States. \\ ${ }^{3}$ Department of Electrical \& Computer Engineering, Michigan Technological University, \\ Houghton, MI, United States. \\ * corresponding author:pearce@mtu.edu
}

\begin{abstract}
Although the environmental benefits of recycling plastics are well established and most geographic locations within the U.S. offer some plastic recycling, recycling rates are often low. Low recycling rates are often observed in conventional centralized recycling plants due to the challenge of collection and transportation for high-volume low-weight polymers. The recycling rates decline further when low population density, rural and relatively isolated communities are investigated because of the distance to recycling centers makes recycling difficult and both economically and energetically inefficient. The recent development of a class of open source hardware tools (e.g. RecycleBots) able to convert post-consumer plastic waste to polymer filament for 3-D printing offer a means to increase recycling rates by enabling distributed recycling. In addition, to reducing the amount of plastic disposed of in landfills, distributed recycling may also provide low-income families a means to supplement their income with domestic production of small plastic goods. This study investigates the environmental impacts of polymer recycling. A life-cycle analysis (LCA) for centralized plastic recycling is compared to the implementation of distributed recycling in rural areas. Environmental impact of both recycling scenarios is quantified in terms of energy use per unit mass of recycled plastic. A sensitivity analysis is used to determine the environmental impacts of both systems as a function of distance to recycling centers. The results of this LCA study indicate that distributed recycling of HDPE for rural regions is energetically favorable to either using virgin resin or conventional recycling processes. This study indicates that the technical progress in solar photovoltaic devices, open-source 3-D printing and polymer filament extrusion have made distributed polymer recycling and upcycling technically viable.
\end{abstract}

\section{INTRODUCTION}

Global production of plastic increased by $500 \%$ over the last 30 years and it is expected to continue to grow to 850 million tons/year by 2050 [1-3]. Plastic use results in a substantial environmental burden due to both land and water pollution as plastics take 10 to 450 years to decompose in landfills [4-6]. Plastic processing, use, and disposal also comprise a significant source of energy consumption with the concomitant emissions and additional pollution [7-10]. Rural areas in the U.S. generally have limited recycling opportunities, which makes recycling difficult and burdensome to rural residents, which make up 19\% of the population (60m) [11]. 
Published as: M. Kreiger, G. C. Anzalone, M. L. Mulder, A. Glover and J. M Pearce (2013). Distributed Recycling of Post-Consumer Plastic Waste in Rural Areas. MRS Online Proceedings Library, 1492, mrsf12-1492-g04-06 doi:10.1557/opl.2013.258.

Two recent open-source hardware technological developments, 3-D printers and RecycleBots, offer a new approach to polymer recycling (or upcycling), encompassing the potential for distributed processing to high-value added products, which reverses the historical trend towards centralized manufacturing and recycling facilities. Application of these technologies could induce job creation and allow for residents of rural areas to supplement their income by creating and customizing goods that were historically not available locally.

Highly accurate commercial 3-D printers are useful production and design tools. The development of additive manufacturing for rapid prototyping and 3-D printing in a number of technologies has been substantial [12-16]. Recently, following the open source (OS) model, the RepRap has been developed which can be built for $\sim \$ 500$, greatly expanding the potential user base of 3-D printers. These machines could feasibly be used for small-scale manufacturing in isolated regions or as an enabling tool for green manufacturing [17]. Commercial extrusion of plastic utilizes a screw to move material through a heated barrel where it is compressed, melted, mixed and forced through a die [18]. A small-scale plastic extruder using these principles to turn waste plastic into a growth medium for plants [19], has been modified to create a new, semiautomated open source "RecycleBot" to prepare RepRap feedstock from household plastic waste such as milk jugs and laundry detergent containers [20].

The primary expense of operating a 3-D printer is the filament or " $3-\mathrm{D}$ ink" and thus the operating costs and environmental impact of the RepRap can be further reduced using waste plastics as feedstock and may provide an incentive for distributed, in-house recycling of plastic waste [17]. Baechler et al., have demonstrated acceptable 3-D filament production from a RecycleBot using high density polyethylene (HDPE) [20]. Several other open-source filament fabricators have also been recently developed (e.g. Filabot [21], Lyman Filament Extruder[22]), which could be utilized as waste plastic RecycleBots. HDPE, recycled plastic number "2", is used primarily for packaging, pipes, and plastic lumber. HDPE poses known challenges for recycling, but with the addition of a stabilizing system the recycled output can have similar properties to virgin resin [23].

This study explores the technical potential of using a distributed network of RecycleBots to process HDPE waste into 3-D printing feedstock. A life cycle analysis (LCA) of energy consumption is performed for this distributed approach and compared to the conventional recycling in rural areas. In this radical distributed approach the recycling process occurs at the site of consumption, with the plastic processed by the consumer. These results are discussed to draw conclusions about the viability of distributed recycling.

\section{METHODS}

The distributed recycling process includes: cleaning, cutting, and shredding plastic bottles and other plastic recyclables of the same plastic type (Fig. 1a). These processes are assumed to be completed by the consumer on site and are not included in the analysis. The shreds of plastic are put into a waste plastic extruder (RecycleBot: Fig. 1b) described in detail by Baechler et al. [20]. The RecycleBot melts down the plastic and creates a 3mm filament that can be used in a RepRap or other type of 3-D printer (Fig. 1c). The energy consumption for the RecycleBot was measured during extrusion with a multimeter $( \pm 0.005 \mathrm{kWh})$. The stages included in this study were auger drive and heating (shredding was previously shown to have negligible energy consumption using less than 3\% of the energy of the other stages and could be accomplished manually [20]). 
Published as: M. Kreiger, G. C. Anzalone, M. L. Mulder, A. Glover and J. M Pearce (2013). Distributed Recycling of Post-Consumer Plastic Waste in Rural Areas. MRS Online Proceedings Library, 1492, mrsf12-1492-g04-06 doi:10.1557/opl.2013.258.

The LCA software SimaPro 7.2 was used to get the cumulative energy demand (CED 1.07) for each case along with the database EcoInvent v2.0. For distributed recycling based on the electricity usage of the RecycleBot, (Electricity, Production Mix, US) was used as an input to make the results of this study as generalizable as possible. The cut-off method was used in each case, where the initial virgin resin production is not considered in the recycled energy demand. This described method using SimaPro was used for the experimental RecycleBot value, in order to be able to do a direct comparison between each method of recycling HDPE.

For the rural area, the small, geographically isolated town of Copper Harbor, MI was used. Located at the tip of the Keweenaw Peninsula, Copper Harbor is a 48 mile drive from the nearest recycling collection center in Houghton, MI and there is no curbside pickup. Plastic waste is transported by semi-truck from Houghton to the processing center in Green Bay, WI, 212 miles away. The average household generates 16.9 pounds of mixed recyclables per week of which 5.2 pounds or 31\% is HDPE [24]. Two scenarios are considered: recycling (1) biweekly or (2) monthly where transportation is provided by passenger vehicles with a mixed recyclable load. SimaPro was used to determine the cumulative energy demand using (Operation, passenger car, petrol, fleet average 2010, Switzerland). The input used for the Houghton to Green Bay trip was (Operation, lorry 3.5-20t, full, fleet average, Switzerland) the return trip was considered using a similar input for (empty). The Swiss data has been previously shown to be reliable and can be expected to representative of U.S. energy uses. All of these values were considered for $1 \mathrm{~kg}$ of recycled HDPE, to account for the $8 \%$ waste in processing [24].
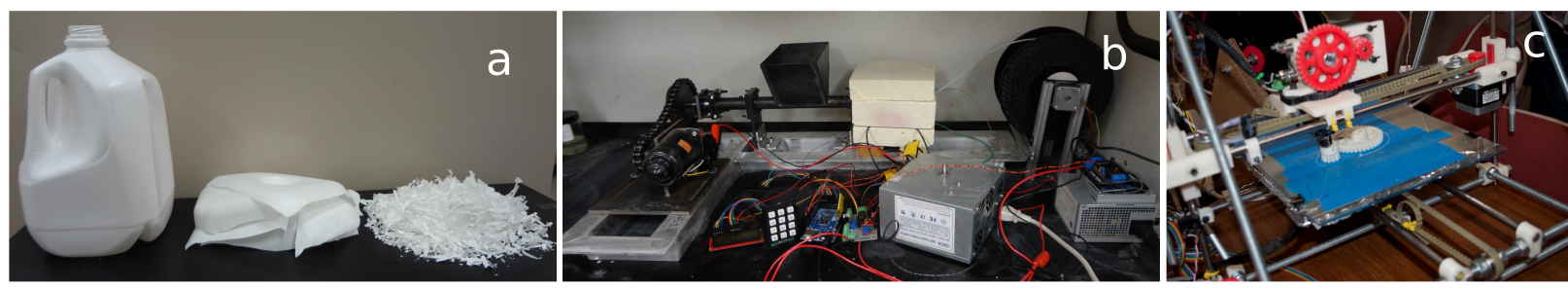

Fig. 1: Distributed HDPE Recycling. a) Cutting and shredding HDPE milk jug, b) Extruding 3-D printing filament in RecycleBot (improved performance was observed wrapping the front and back of the extruder and the insulation with Kapton tape, not shown here for clarity), c) RepRap 3-D printer self-replicating.

An LCA study of conventional HDPE recycling was previously completed [24] using confidential information from recycling companies and was used here to quantify the impact and energy demand for conventional centralized recycling. The energy from the transport of plastics (collection) was added to the additional energy demand required to process the plastic of 7.513 MJ per kg HDPE recycled, using the cut-off weight based method excluding collection [24], to give an estimate of the total cumulative energy demand.

\section{RESULTS AND DISCUSSION}

Table 1 summarizes the energy demand for distributed recycling of HDPE using the distributed RecycleBot, HDPE virgin resin, and the conventional method of recycling in rural areas under the conditions of biweekly or monthly trips to the collection center. 
Published as: M. Kreiger, G. C. Anzalone, M. L. Mulder, A. Glover and J. M Pearce (2013). Distributed Recycling of Post-Consumer Plastic Waste in Rural Areas. MRS Online Proceedings Library, 1492, mrsf12-1492-g04-06 doi:10.1557/opl.2013.258.

In the distributed recycling case the RecycleBot required $0.06 \mathrm{kWh}$ for initial heating, and $0.0036 \mathrm{kWh} / \mathrm{m}$ of filament. The total energy used for filament production was $0.694 \mathrm{kWh}$ (2.5 MJ) per kg of recycled HDPE filament. 2.5 MJ per kg recycled HDPE was input into SimaPro 7.2 using cumulative energy demand 1.07 and evaluated with the only input being the electricity production mix of the U.S., from the EcoInvent 2.0 database, which gives the cumulative energy demand of 8.74 MJ shown in Table 1.

Table 1: Energy Demand and Reduction for Various Recycling Cases

\begin{tabular}{|c|c|c|}
\hline Case & $\begin{array}{l}\text { Energy Demand } \\
\text { (MJ/kg HDPE) }\end{array}$ & $\begin{array}{c}\text { Percent Reduction }(\Delta \%) \\
\text { for Distributed } \\
\text { Recycling }^{\mathrm{c}}\end{array}$ \\
\hline $\begin{array}{l}\text { Distributed Recycling: } \\
\text { Insulated RecycleBot }\end{array}$ & 8.74 & -- \\
\hline Virgin Resin ${ }^{a}$ & 79.7 & 89 \\
\hline $\begin{array}{c}\text { Centralized Recycling }{ }^{\mathrm{b}}-\text { Rural: } \\
\text { Copper Harbor (monthly) }\end{array}$ & 28.4 & 69 \\
\hline $\begin{array}{l}\text { Centralized Recycling }{ }^{\text {b }} \text { - Rural: } \\
\text { Copper Harbor (bi-weekly) }\end{array}$ & 48.9 & 82 \\
\hline \multicolumn{3}{|c|}{$\begin{array}{l}\text { Notes: a. [26], b. Estimate based on [24], } \\
\text { c. Percent reduction }=(\text { Central-Distributed }) / \text { Central*100 }\end{array}$} \\
\hline
\end{tabular}

Energy demand values in the RecycleBot cases are higher than the experimental measurements as they include the additional energy to produce the electricity used. It should be pointed out that, the virgin resin embodied energy of $79.67 \mathrm{MJ} / \mathrm{kg}$ HDPE [25], underestimates the energy required, as additional energy is needed to turn the resin into filament. Even with this underestimate, distributed recycling reduces the energy demand of HDPE over the virgin resin by a substantial $89 \%$.

When comparing the conventional rural recycling to distributed recycling, distributed recycling can reduce the energy demand by at least $69-82 \%$ using conventional electricity in rural areas such as the case study. Monthly and biweekly trips for recycling result in an energy demand of at least 28.4 MJ and 48.9 MJ per kg of recycled HDPE. For rural locations, the energy values for transport can only be reduced by transporting more materials per trip, hence the potential for taking monthly trips instead of biweekly trips. If conventional recycling is used, the best option is to transport as many recyclables as possible and minimize the frequency of these trips.

A sensitivity analysis was done based on the miles transported for the rural case as seen in Fig. 2. It was found that for rural locations over one mile from the nearest collection center that will need to make trips biweekly, it requires less energy to use distributed recycling powered conventionally. For rural locations over two miles from the nearest collection center, less energy is required for distributed recycling than conventional, even when only making monthly trips.

The cumulative energy of the distributed case could be further reduced using a low-embodied energy distributed generation technology such as solar photovoltaic (PV) systems [25]. Conventional cases could be similarly improved, however, the distributed nature of PV couples favorably with the distributed recycling technology. As the costs have decreased for distributed 
Published as: M. Kreiger, G. C. Anzalone, M. L. Mulder, A. Glover and J. M Pearce (2013). Distributed Recycling of Post-Consumer Plastic Waste in Rural Areas. MRS Online Proceedings Library, 1492, mrsf12-1492-g04-06 doi:10.1557/opl.2013.258.

PV [27], a PV-powered distributed polymer recycling process becomes potentially economically as well as energetically viable. This technical progress coupled to new peer-to-peer financing provides the potential for rural communities to become more autonomous while improving local economies [28]. Work is underway now to merge these technologies at several institutions.

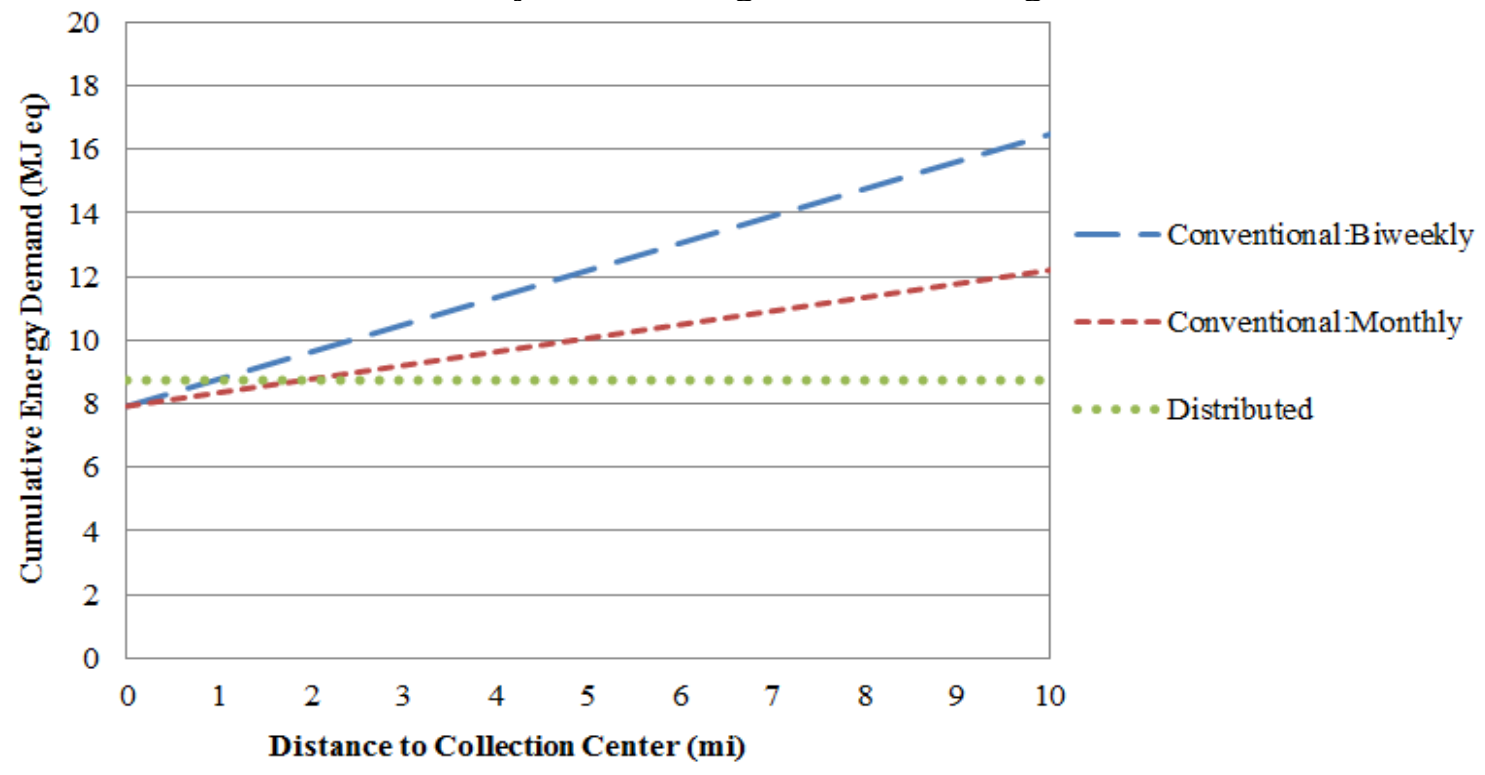

Fig. 2: Energy demand vs distance from recycling center (biweekly and monthly trips) compared to distributed recycling using the RecycleBot (Distributed).

The recycled filament could be used to print any of the 50,000 open-source designs in the Thingiverse database on in-home 3-D printers or it could be sold on the open market. Future work on the energy demand of distributed recycling of other plastics that can be used in 3-D printers needs to be considered. Also, future work on tuning printing with HDPE needs to be accomplished, potentially necessitating the design of an open-source environmental chamber.

\section{CONCLUSIONS}

The results of this LCA study indicate that distributed recycling of HDPE for rural regions is energetically favorable to either using virgin resin or conventional recycling processes. In the case study explored, embodied energy savings of 69 to $82 \%$ were found for RecycleBot technology over centralized recycling. These results provide further support for minimizing transportation distances for recycling to minimize environmental impact. This study indicates that the technical progress in solar photovoltaic devices, open-source 3-D printing and polymer filament extrusion have made distributed polymer recycling and upcycling technically viable and potentially economically advantageous for rural residents in both the US, but also the $\sim 3$ billion people globally living in rural areas.

\section{ACKNOWLEDGMENTS}

The authors would like to acknowledge technical support from A. Vora. This research was supported by Sustainable Futures Institute and a McArthur Research Internship. 
Published as: M. Kreiger, G. C. Anzalone, M. L. Mulder, A. Glover and J. M Pearce (2013). Distributed Recycling of Post-Consumer Plastic Waste in Rural Areas. MRS Online Proceedings Library, 1492, mrsf12-1492-g04-06 doi:10.1557/opl.2013.258.

\section{REFERENCES}

1. L.C.-M. Lebreton, S.D. Greer, J.C. Borrero. Marine Pollution Bulletin. 54, 3 (2012).

2. L. Shen, J. Haufe, M.K. Patel. Product Overview and Market Projection of Emerging Bio-based Plastics PRO-BIP 2009, Utrecht University Final Report, (2009).

3. A. Lotfi, Polymer Recycling. WWW document, (http://www.lotfi.net/recycle/plastic.html).

4. J.F. Rees. J. Chem. Technol. Biotechnol. 30, 1 (1980).

5. J.G.B. Derraik. Marine Pollution Bulletin. 44 (2002).

6. U.S. National Park Service. Time it takes for garbage to decompose in the environment. WWW document, (http://des.nh.gov/organization/divisions/water/wmb/coastal/ trash/documents/marine debris.pdf).

7. U. Arena, M.L. Mastellone, F. Perugini. Int. J. of Life Cycle Assessment. 8, 2 (2003).

8. F. Perugini, M.L. Mastellone, U. Arena. Environ. Prog. 24, 2 (2005).

9. P.M. Subramanian. Resources, Conservation and Recycling. 28, 3-4 (2000).

10. A. Björklund, G. Finnveden. Resources, Conservation and Recycling. 44, 4 (2005)

11. U. S. Census Bureau, 2010 Census Urban and Rural Classification and Urban Area Criteria. WWW doc. (http://www.census.gov/geo/www/ua/2010urbanruralclass.html).

12. S. Upcraft, R. Fletcher. Assembly Automation. 23, 4 (2003).

13. I. Gibson, D.W. Rosen, B. Stucker. Physics Procedia. 5 (2010).

14. V. Petrovic, J.V.H. Gonzalez, O.J. Ferrando, J.D. Gordillo, J.R.B. Puchades, L.P. Griñan. Int. J. of Production Research. 49, 4 (2010).

15. A. Gebhardt, F. Schmidt, J. Hötter, W. Sokalla, P. Sokalla. Physics Procedia. 5, 2 (2010).

16. N.B. Crane, J. Tuckerman, G.N. Nielson. Rapid Prototyping Journal. 17, 3 (2011).

17. J. M Pearce, C. Morris Blair, K. J. Laciak, R. Andrews, A. Nosrat, I. Zelenika-Zovko, J. of Sust. Dev. 3(4), 17 (2010).

18. D. Rosato. Plastics Processing Data Handbook. 2nd ed.(Springer-Verlag, 1997).

19. R. Torcellini. Plastic extruder for growing media. WWW document, (http://web4deb.blogspot.com/2010/12/plastic-extruder-for-growing-media.html).

20. C. Baechler, M. DeVuono, J.M. Pearce. Distributed recycling of waste polymer into reprap feedstock. Rapid Prototyping Journal, 19(2) (in press) March 2013.

21. Filabot Personal Filament Maker. WWW document, (http://filabot.com).

22. Lyman Filament Extruder. WWW document, (http://www.thingiverse.com/thing:30642).

23. M. Loultcheva, M. Proietto, N. Jilov, F.P. La Mantia. Polymer Degradation and Stability. 57, 1 (1997).

24. Franklin Associates, Life cycle inventory of 100\% postconsumer HDPE and PET recycled resin from postconsumer containers and packaging, (2011).

25. G. Hammond, C. Jones. Inventory of carbon \& energy (ICE) Version 1.6a,Bath U.(2008).

26. J. Pearce, A. Lau, Net Energy Analysis For Sustainable Energy Production From Silicon Based Solar Cells. Proc. of A. Soc. of Mech. Eng. Solar, Cambell-Howe (Ed.), (2002).

27. K. Branker, M. J.M. Pathak, J. M. Pearce, A Review of Solar Photovoltaic Levelized Cost of Electricity”, Renewable \& Sustainable Energy Reviews 15, 4470 (2011).

28. K. Branker, E. Shackles, J. M. Pearce, Peer-to-Peer Financing Mechanisms to Accelerate Renewable Energy Deployment. J. of Sust. Finance \& Investment 1(2), 138 (2011). 